\title{
ECONOMÍA Y FINANZAS EN PANAMÁ: UNA IMPERATIVA EVOCACIÓN A LOS DERECHOS HUMANOS
}

\author{
ECONOMY AND FINANCE IN PANAMA: AN IMPERATIVE EVOCATION \\ TO HUMAN RIGHTS
}

Juan Pablo Bohoslavsky

Recibido: 22/03/2018 - Aceptado: 18/05/2018

\begin{abstract}
Resumen
Este artículo analiza la economía y finanzas de Panamá desde una perspectiva de derechos humanos. Primero presenta las implicaciones adversas de las corrientes financieras ilícitas en materia derechos humanos. Luego describe el marco legal e institucional panameño, en particular las obligaciones y compromisos internacionales del país, así como el sector bancario y financiero del país. También se presentan los llamados "papeles de Panamá", tanto la irrupción del escándalo, las disposiciones adoptadas por el gobierno así como las medidas adicionales que aún resultan necesarias. Se discuten asimismo cuestiones vinculadas al crecimiento económico del país, la desigualdad y los derechos humanos, así como se analizan críticamente las implicaciones de proyectos de infraestructura sobre los derechos humanos de las personas y los grupos en Panamá, incluidos los pueblos indígenas. Luego de las conclusiones se presentan recomendaciones que el autor efectuó al gobierno panameño como Experto Independiente de la ONU luego de su visita al país.
\end{abstract}

Palabras clave: Panamá, derechos humanos, finanzas, economía, corrientes financieras ilícitas.

\begin{abstract}
This article analyses the economy and finances of Panama from a human rights perspective. It first presents the adverse implications of illicit financial flows on human rights. It then describes the Panamanian legal and institutional framework, in particular the country's international obligations and commitments, as well as the banking and financial sector of the country. It also presents the "Panama Papers," including the scandal outbreak, policies adopted by the government as well as those additional measures still needed. Issues related to the country's economic growth, inequality and human rights are also discussed, and the implications of infrastructure projects for persons and groups in Panama, including indigenous peoples, are critically studied. After the conclusions the recommendations that the
\end{abstract}


author made to the Panamanian government as Independent Expert of the UN after his visit to the country are presented.

Keywords: Panama, human rights, finance, economy, illicit financial flows.

\section{Introducción ${ }^{1,2}$}

Este artículo se organiza en cuatro secciones. La primera sección presenta las implicaciones adversas de las corrientes financieras ilícitas en materia derechos humanos. La segunda sección describe el marco legal e institucional panameño, en particular las obligaciones y compromisos de Panamá en materia de derechos humanos, así como el sector bancario y financiero de Panamá. En la tercera sección se presentan los llamados "papeles de Panamá", tanto la irrupción del escándalo, las disposiciones adoptadas por el gobierno como las medidas adicionales que aún resultan necesarias. La cuarta sección discute cuestiones vinculadas al crecimiento económico del país, la desigualdad y los derechos humanos. La quinta sección analiza críticamente las implicaciones de proyectos de infraestructura sobre los derechos humanos. Finalmente, se presentan las conclusiones y recomendaciones.

\section{Las corrientes financieras ilícitas afectan a los derechos humanos}

En su Resolución 31/11, la cual contó con el voto favorable de Panamá, el Consejo de Derechos Humanos reconoció que las corrientes financieras ilícitas, entre estas la evasión fiscal por particulares con grandes patrimonios, la evasión fiscal comercial mediante la emisión de facturas comerciales falsas y la elusión de impuestos por empresas transnacionales, contribuyen a que se acumule una deuda insostenible, al privar a los gobiernos de ingresos fiscales internos, lo que puede obligarlos a recurrir a empréstitos externos. El Consejo subraya de manera explícita los vínculos entre la desigualdad, la exclusión social y la aparición de crisis financieras, que a su vez afectan negativamente a los derechos humanos. Esencialmente, el Consejo alienta a los Estados a que estudien nuevas vías para reformar partes de su ordenamiento jurídico con miras a elaborar un régimen fiscal más equitativo.

Como se indica en el informe temático de 2015las corrientes financieras ilícitas y los derechos humanos se relacionan entre sí de diversas formas, especialmente debido a que las salidas ilícitas de fondos privan a los gobiernos de recursos esenciales necesarios para establecer instituciones eficaces e independientes y para hacer efectivos los derechos humanos (Naciones Unidas 2015). A menudo, la falta de suficientes recursos públicos afecta a los grupos más vulnerables y marginados de la sociedad. Las corrientes financieras ilícitas debilitan el estado de derecho y constituyen 
un impedimento para las garantías procesales, lo que tiene efectos duraderos en la igualdad ante la ley. Desempeñan un papel decisivo en el aumento de la impunidad, la corrupción y el abuso de autoridad, lo que puede crear un terreno propicio a las violaciones de los derechos humanos.

Pocos cuestionarán la premisa de que las corrientes financieras ilícitas son un reto mundial, que afecta tanto a las economías desarrolladas como a las economías en desarrollo. No son un accidente ni un subproducto del mercado, sino que a menudo parecen el resultado de un alto grado de impunidad y de prácticas sancionadas por el Estado, una regulación insuficiente y el uso indebido de instrumentos financieros complejos con el fin de evitar la rendición de cuentas y la trazabilidad. No cabe duda de que es posible atacarlas y contrarrestarlas por medio de mecanismos de cooperación internacional y de responsabilidad compartida entre todos los países.

De igual forma, los esfuerzos realizados por un solo país, sin que haya cambios estructurales en otras jurisdicciones o esfuerzos internacionales para combatir la opacidad, rara vez producirán resultados significativos. En ese contexto, celebré la adopción del compromiso mundial de reducir significativamente las corrientes financieras ilícitas en el marco de la meta 16.4 de la Agenda 2030 para el Desarrollo Sostenible. Asimismo, se felicitó que los Estados Miembros de las Naciones Unidas lo adquirieran, al mismo tiempo que se comprometieron a reducir la desigualdad en los países y entre ellos como Objetivo de Desarrollo Sostenible 10. La restricción de las corrientes financieras ilícitas significaría una contribución muy sustancial a la reducción de las desigualdades de patrimonio e ingresos en los planos nacional y mundial.

En relación con lo anterior, la Agenda de Acción de Addis Abeba de la Tercera Conferencia Internacional sobre la Financiación para el Desarrollo, subraya que la movilización y la utilización eficaz de los recursos nacionales son esenciales para la consecución de los Objetivos de Desarrollo Sostenible. La reducción de las salidas ilícitas de fondos debidas al fraude en la facturación ${ }^{3}$ los abusos fiscales, la corrupción y las actividades delictivas resulta fundamental para incrementar la movilización de recursos internos. Ambas acciones están intrínsecamente conectadas y son esenciales para velar por que todos los Estados dispongan de suficiente espacio fiscal, no solo para lograr los Objetivos de Desarrollo Sostenible, sino, sobre todo, para la protección y la efectividad de los derechos humanos.

Los recursos públicos son necesarios para garantizar los derechos civiles, culturales, económicos, políticos y sociales y para cumplir las obligaciones de los Estados dimanantes de los tratados internacionales de derechos humanos. Ningún Estado puede funcionar correctamente sin un sistema judicial independiente debidamente financiado, y sin agentes del orden debidamente capacitados para proteger el estado de derecho y la seguridad y los derechos de quienes residen en su territorio. Del mismo modo, es necesario realizar un gasto público considerable para garantizar el acceso universal a un sistema educativo, hospitales y centros de salud 
que funcionen debidamente, así como el acceso a medicamentos esenciales y diversas formas de bienestar social.

Si bien, son numerosos los fenómenos que contribuyen a las corrientes financieras ilícitas, se estima que la mayor parte de estas proviene de transacciones fiscales transfronterizas ilícitas (Naciones Unidas 2016). De hecho, el propósito de los movimientos internacionales de capital que transfieren activos financieros o utilidades contables a jurisdicciones con baja (o ninguna) tributación y con estrictas normas de confidencialidad consiste esencialmente en reducir o evitar el pago de impuestos. Las medidas orientadas a frenar las corrientes financieras ilícitas vinculadas con cuestiones tributarias deberían minimizar la evasión de impuestos por parte de individuos con alta riqueza; la evasión de impuestos de las empresas mediante el fraude en la facturación y la elusión fiscal basada en la utilización abusiva de precios de transferencia por las empresas transnacionales.

Las estimaciones mundiales indican que una gran cantidad de la riqueza está depositada en centros offshore, para aprovechar el secreto bancario y el uso de fideicomisos y sociedades anónimas para ocultar la identidad de los beneficiarios finales en jurisdicciones extranjeras. El objetivo perseguido suele ser evadir o reducir el pago de impuestos o bien ocultar activos robados. A veces esos instrumentos también se utilizan para ocultar ganancias producto de la corrupción u otras actividades delictivas. Aunque la mayoría de los activos depositados en centros offshore puedan haber sido obtenidos mediante actividades económicas lícitas, el hecho de ocultarlos con el fin de evadir el pago de impuestos los convierte en ilícitos. La omisión de declarar esos activos constituye una conducta delictiva en casi todas las jurisdicciones, especialmente cuando se trata de sumas importantes.

Según estimaciones de 2015, la riqueza privada no declarada depositada en el extranjero oscila entre los 24 y los 36 billones de dólares de los Estados Unidos. (Naciones Unidas 2016) Se ha calculado que la cantidad relativa de la riqueza de países en desarrollo mantenida en el extranjero es mucho mayor que la de países desarrollados, entre el $20 \%$ al $30 \%$ en el caso de muchos países latinoamericanos y africanos. En cuanto a la desigualdad en la tenencia de riqueza offshore, se ha calculado que entre el $85 \%$ y el $90 \%$ de esas riquezas son propiedad de menos de 10 millones de personas, que solo representan el $0.014 \%$ de la población mundial (Naciones Unidas 2016 párrs. 12 y 13). En otro estudio se ha concluido que la probabilidad de que se oculten activos aumenta mucho a la par que la riqueza, incluso dentro de los grupos más ricos. En consecuencia, la riqueza de los centros offshore está sumamente concentrada. Según estimaciones del autor, el 0.01 por ciento más rico de la población posee alrededor del $50 \%$ de la riqueza (Alstadsaeter, Johannesen y Zucman 3). 


\section{Marco legal e institucional panameño}

\section{Obligaciones y compromisos de Panamá en materia de derechos humanos}

Panamá ha ratificado - y asumido así las consiguientes obligaciones- la mayoría de los tratados internacionales de derechos humanos, entre ellos, el Pacto Internacional de Derechos Económicos, Sociales y Culturales, el Pacto Internacional de Derechos Civiles y Políticos, la Convención Internacional sobre la Eliminación de Todas las Formas de Discriminación Racial, la Convención sobre la Eliminación de Todas las Formas de Discriminación contra la Mujer, la Convención sobre los Derechos del Niño y la Convención sobre los Derechos de las Personas con Discapacidad. Todos esos instrumentos incluyen disposiciones relativas a la no discriminación y al ejercicio efectivo de los derechos económicos, sociales y culturales. ${ }^{4}$ En el plano regional, Panamá ratificó la Convención Americana sobre Derechos Humanos y su Protocolo Adicional en materia de Derechos Económicos, Sociales y Culturales. ${ }^{5}$

Esos tratados internacionales se encuentran reconocidos en el artículo 4 de la Constitución de Panamá, y se han incorporado al derecho interno mediante su ratificación por ley (art. 159.3). La Corte Suprema de Panamá, en sentencia de 21 de agosto de 2008, estableció que todos los tratados de derechos humanos vigentes forman parte del bloque de constitucionalidad, lo que significa que los derechos contenidos en los instrumentos internacionales de derechos humanos tienen el mismo rango que las normas constitucionales, por lo que consolidan y amplían las garantías ya reconocidas en la Constitución (Naciones Unidas 2017 párrs. 252 -254).

Un aspecto fundamental para el ejercicio efectivo de los derechos humanos consagrados en esos instrumentos es la obligación que tienen los Estados partes de adoptar las medidas apropiadas hasta el máximo de los recursos de que dispongan para garantizar progresivamente la plena efectividad de los derechos económicos, sociales y culturales. Según ha indicado el Comité de Derechos Económicos, Sociales y Culturales, las medidas apropiadas no solo son las legislativas, sino también las de carácter administrativo, financiero, además de la provisión de recursos efectivos ante las violaciones de los derechos humanos. ${ }^{6}$ Las medidas financieras incluyen, entre otras, las políticas tributarias y fiscales, así como la regulación de las acciones y omisiones de los agentes financieros y las empresas comerciales de los sectores público y privado. Los agentes que operan en el sector financiero son bancos, entidades financieras, contadores, aseguradoras y bufetes de abogados, entre otros.

Otras fuentes pertinentes de criterios y normas son los Principios rectores sobre la deuda externa y los derechos humanos, ${ }^{7}$ y los Principios Rectores sobre las Empresas y los Derechos Humanos. ${ }^{8}$ 
Un aspecto esencial del derecho internacional de los derechos humanos son las obligaciones de los Estados de respetar, proteger y hacer efectivos todos los derechos humanos de todas las personas o grupos que se encuentren en su territorio o bajo su jurisdicción. El deber de proteger conlleva la adopción de medidas para velar por que las acciones realizadas por terceros amparados por el ordenamiento jurídico del Estado, como, por ejemplo, entidades financieras y empresas comerciales, no propicien abusos contra los derechos humanos ni socaven el disfrute de los derechos humanos en el país y en el extranjero. ${ }^{9}$ En otras palabras, todos los Estados tienen la responsabilidad de velar por que las empresas que operen en su territorio y estén sujetas a su jurisdicción respeten los derechos humanos, y sobre todo, porque las acciones u omisiones de esas empresas no tengan efectos adversos en otras jurisdicciones, por ejemplo, al participar en la fuga de activos y capital que deberían ser declarados y gravados (Naciones Unidas 2011).

\section{El sector bancario y financiero de Panamá}

Panamá es un centro bancario y financiero de importancia crucial, que cuenta con más de 90 bancos, de los que 50 disponen de una licencia general para realizar actividades bancarias a nivel nacional e internacional. Panamá cuenta con un sector bancario y financiero que goza de un nivel elevado de liquidez. La Superintendencia de Bancos obliga a los bancos nacionales a mantener un índice de liquidez superior al 30 por ciento, lo que en última instancia protegió a la economía local de los peores efectos de la crisis financiera mundial del pasado decenio.

Actualmente, más del 30 por ciento de los depósitos en bancos con licencia general de Panamá proceden del extranjero, principalmente de América Latina, lo que pone de relieve el riesgo que pueden correr los bancos panameños de recibir fondos de procedencia dudosa (Hernández, Martínez y Patrie párr. 7). La situación podría ser aún peor, ya que ese porcentaje no incluye los casos en que, por ejemplo, una sociedad panameña puede ser propiedad de inversores extranjeros, aunque los depósitos se considerarían nacionales (Solís párr. 6).

Según la Superintendencia de Bancos, los activos del centro bancario internacional, en marzo de 2017, ascendían a 120140 millones de dólares, mientras que los activos administrados por los bancos nacionales con licencia general solo eran de 100290 millones de dólares. En términos financieros, el sistema bancario de Panamá ha registrado una rentable tendencia alcista. Por ejemplo, las utilidades del centro bancario internacional aumentaron un $12 \%$ durante el primer trimestre de 2017 (un beneficio neto de 486 millones de dólares entre enero y marzo de 2017), y las estimaciones anuncian resultados similares o mejores para el resto del año. Los bancos nacionales que solo tienen una licencia general presentan resultados aún mejores, ya que en marzo de 2017 habían totalizado 354 millones de dólares de 
utilidades, lo que supone un 18.4 por ciento más que en 2016 (Superintendencia de Bancos de Panamá 7).

El sector financiero y bancario de Panamá es solo un componente de una plataforma amplia y muy integrada de servicios y logística. Considerado como vasto y sofisticado, es uno de los más utilizados en todo el mundo, especialmente para las transacciones comerciales efectuadas entre América Latina y el resto del mundo. La plataforma de servicios incluye el Canal de Panamá y dos de los tres puertos más importantes de América Latina y el Caribe, Colón y Balboa, que representan el 15 por ciento del movimiento de carga de la región (CEPAL infografía). Además, hay 19 zonas francas, de las que 11 se concentran en las ciudades de Panamá y Colón (Dirección Nacional de Zonas Francas párr. 2). Esas zonas, reguladas por la Ley N. 32 de 2011, ofrecen ventajas fiscales, normas simplificadas e incentivos en materia de migración y empleo, especialmente ideados para atraer el comercio exterior.

La historia de Panamá está directamente ligada a su actividad bancaria y financiera, y hasta la fecha se ha beneficiado de su situación geográfica estratégica. La primera Ley Bancaria, aprobada en 1970,10 dispuso la creación de la Comisión Bancaria Nacional como entidad reguladora y permitió atraer a prestigiosos bancos internacionales. Se la consideró como un pilar para el establecimiento de un centro bancario internacional especializado en las operaciones en el extranjero, aprovechando los incentivos tributarios, una plaza bilingüe, un sistema de telecomunicaciones que permitía efectuar transacciones financieras internacionales, y un sistema dolarizado, ${ }^{11}$ El centro bancario internacional creció y se especializó principalmente, aunque no de forma exclusiva, en el financiamiento destinado a América Latina.

La crisis política de 1988 causó una caída de los activos cercana a los 14000 millones de dólares y el cierre del sistema bancario por nueve semanas y media. Se permitían únicamente las operaciones internacionales. La crisis acabó con la intervención militar de los Estados Unidos en Panamá, en diciembre de 1989.

Entre 1990 y 1999 volvieron a aumentar los activos del centro financiero, y en 1998 se aprobaron nuevas leyes ${ }^{12}$ con fines de adaptación a las normas establecidas por el Comité de Supervisión Bancaria de Basilea. Cabe destacar que la nueva legislación otorgó autonomía administrativa y financiera a la Superintendencia de Bancos.

El 10 de agosto de 1998, Panamá ratificó la Convención Interamericana contra la Corrupción y el 4 de junio de 2001, firmó la declaración relativa al Mecanismo de Seguimiento de la Implementación de la Convención. El 23 de septiembre de 2005 ratificó la Convención de las Naciones Unidas contra la Corrupción. ${ }^{13}$ Mediante el Decreto Ejecutivo N. 52 de 30 de abril de 2008, se elaboró un amplio marco de regulación bancaria, con el propósito de cumplir con las normas internacionales.

En 2014, el Grupo de Acción Financiera incluyó a Panamá en la lista de países que presentaban deficiencias estratégicas en los ámbitos de las medidas contra el lavado de dinero y la lucha contra el financiamiento del terrorismo, conocida como "la lista 
gris" (Fondo Monetario Internacional). Aunque la medida suscitó serias críticas, sirvió de punto de inflexión para el inicio de reformas y la actualización del marco regulatorio a fin de prevenir el lavado de dinero y el financiamiento del terrorismo en el país. Como resultado de ello, las autoridades de Panamá desplegaron un plan de acción para obtener mejores resultados y minimizar la opacidad de las transacciones. ${ }^{14}$ Cabe señalar que, en febrero de 2016, el Grupo de Acción Financiera reconoció los importantes avances conseguidos en la prevención del lavado de capitales y el financiamiento del terrorismo y retiró a Panamá de la lista de las jurisdicciones objeto de vigilancia.

En parte, como consecuencia de su inclusión en la "lista gris", el 28 de abril de 2015 se produjo un hecho importante, al entrar en vigor la Ley N. 23 de 2015, de prevención del blanqueo de capitales, el financiamiento del terrorismo y el financiamiento de la proliferación de armas de destrucción masiva. La Ley regula varios organismos de supervisión, las entidades públicas y privadas, y las personas naturales y jurídicas. Establece mecanismos de debida diligencia para el registro, la presentación y la identificación de información acerca de los beneficiarios finales, lo que también se conoce como el principio "conozca a su cliente". Con arreglo a la Ley se creó asimismo una unidad de inteligencia financiera, y la Intendencia de Supervisión y Regulación de Sujetos no Financieros, tales como la Zona Libre de Colón, empresas de envío de remesas, la lotería nacional, casas de cambio de moneda, casinos, empresas de construcción e inmobiliarias y comerciantes de piedras preciosas.

Como especifica la Organización de Cooperación y Desarrollo Económicos (OCDE), los artículos 27 y 28 de la Ley N. 23 de 2015 establecen distintas medidas de debida diligencia para las personas naturales y jurídicas. En el caso de las personas naturales, el agente residente debe verificar la identidad del cliente, comprobar la autorización de la persona que esté actuando en nombre de otra, identificar al beneficiario final y tomar las medidas razonables para verificar la información y documentación que se obtenga de cada una de las personas naturales que se identifiquen como beneficiarios finales. En el caso de las personas jurídicas u otras estructuras, el agente residente debe solicitar las certificaciones que evidencien la incorporación y vigencia de las personas jurídicas, lo mismo que la identificación de dignatarios, directores, apoderados, firmantes y representantes legales; identificar y tomar medidas razonables para verificar el beneficiario final usando información relevante obtenida de fuentes confiables, y conducir la debida diligencia que corresponda para las personas naturales que actúen en calidad de administradores, representantes, apoderados, beneficiarios y firmantes de la persona jurídica (OCDE 2016 párrs. 90-104).

Con arreglo al artículo 29, se establece expresamente que los sujetos obligados financieros deberán mantener actualizados los registros relativos a los cambios de propiedad, los propietarios legales y los beneficiarios finales de sus clientes. El Decreto Ejecutivo N. .363 de 13 de agosto de 2015 aclaró que los sujetos obligados no financieros y profesionales que realicen actividades sujetas a supervisión también deberán 
mantener registros sobre las transacciones e información actualizada de sus clientes obtenida mediante las medidas de debida diligencia (art. 19).

Asimismo, los sujetos obligados financieros y no financieros, así como los profesionales que realicen actividades sujetas a supervisión, incluidos los agentes residentes, están obligados a resguardar la información y la documentación por un período de cinco años, contado a partir de la terminación de la relación profesional con el cliente (Ley N. 23 de 2015, art. 29). Esa obligación se aplica igualmente a las personas, entidades jurídicas y otros mecanismos legales nacionales y extranjeros.

Se prohíbe a los agentes residentes establecer una relación o realizar una transacción cuando el cliente no facilita el cumplimiento de las medidas pertinentes de debida diligencia; los agentes podrán hacer un reporte de operación sospechosa a la unidad de investigación (art. 36). Existe una sanción general por el incumplimiento de las disposiciones de la Ley, en la cual se prevé la imposición de sanciones específicas, proporcionales y disuasivas por los organismos de supervisión competentes.

En agosto de 2016, al examinar la transparencia del país en materia fiscal, la OCDE concluyó que Panamá cumplía con cuatro de los elementos necesarios, cumplía en gran medida con uno y cumplía parcialmente con dos, y no cumplía tres elementos. La conclusión del informe fue que "a la luz de las calificaciones correspondientes a cada uno de los elementos considerados en conjunto, la calificación global de Panamá es de "No conforme". ${ }^{15}$ En junio de 2017, en el marco del procedimiento de evaluación abreviado de la OCDE, Panamá fue calificado como "Conforme en gran medida a título provisional" gracias a sus progresos en el mejoramiento de su marco jurídico.

\section{Los "papeles de Panamá"}

\section{La irrupción del escándalo}

Antes de que estallara el escándalo de los papeles de Panamá ya se habían comenzado a implantar varias medidas para que el centro bancario de Panamá cumpliera las normas internacionales. El escándalo de abril de 2016 relativo a un bufete de abogados de Panamá, Mossack Fonseca, debe considerarse en el marco de ese contexto histórico.

Quisiera señalar que muchos de mis interlocutores durante mi visita subrayaron la desafortunada utilización del término "papeles de Panamá", la cual sigue perjudicando la imagen internacional del país. Aun cuando gran número de empresas, fideicomisos y transacciones se crearon o efectuaron en Panamá, es posible rastrear su origen hasta distintas jurisdicciones a través del mundo. Asimismo, la mayor parte de los fondos utilizados en esas transacciones proceden del extranjero.

Los llamados "papeles de Panamá" demostraron que se trata de un problema de carácter internacional y que la red de instrumentos y agentes financieros es sumamente 
extensa e intrincada. Los documentos filtrados ilustran las prácticas extensas y complejas que son legales con arreglo al derecho de Panamá, pero que han sido utilizadas por intermediarios financieros de otros países con el fin de ocultar activos y evadir impuestos.

La filtración concierne aproximadamente a 11.5 millones de documentos que ponen al descubierto sociedades offshore de todo el mundo y detalles de las operaciones financieras ocultas de miles de personas de más de 200 países y territorios. Los documentos filtrados abarcan casi 40 años de datos de un solo bufete de abogados, que revelan la existencia de 214488 sociedades offshore, muchas de las cuales operaban en Panamá en 2015, a pesar de que cuando se produjo la filtración ya había aumentado la vigilancia de la evasión extraterritorial a raíz de la crisis financiera de 2007-2008 (Alstadsaeter, Johannesen y Zucman 11). La creación de sociedades offshore no es ilegal en sí misma, ni en Panamá ni en otros lugares.

Ahora bien, la evasión fiscal y el intento de minimizar el pago de impuestos son la razón fundamental de que, durante decenios, personas políticamente expuestas, acaudaladas, empresas y entidades financieras de todo el mundo hayan solicitado los servicios de un bufete de abogados de Panamá para depositar activos financieros provenientes de al menos 20 jurisdicciones.

Aunque Mossack Fonseca no era el único proveedor de servicios offshore domiciliado en Panamá, en aquel momento era al parecer uno de los principales proveedores de ese país. Hay que señalar que la existencia de un número tan elevado de sociedades creadas por un bufete de abogados no significa que todas ellas se utilizaran como pantallas para eludir responsabilidades, cubrir transacciones ilícitas o evadir el pago de impuestos. Ahora bien, la inmensa mayoría de esas sociedades offshore son señaladas como parte de un complejo modelo mundial de negocio que ayuda a que grandes fortunas o empresas oculten su identidad, distanciando a la empresa real del beneficiario final, lo que, a su vez, resulta muy práctico con fines de evasión o elusión fiscal y de lavado de dinero.

A la luz de las estimaciones de que se dispone, los sofisticados servicios descritos anteriormente podrían tener graves consecuencias extraterritoriales en materia de derechos humanos, al reducir los ingresos a disposición de los gobiernos extranjeros para prestar servicios públicos y hacer efectivos los derechos humanos (Naciones Unidas 2015).

\section{Disposiciones adoptadas por el gobierno}

Después del escándalo relativo al bufete de abogados Mossack Fonseca, las principales consecuencias en Panamá fueron dos: se aceleró y profundizó el proceso ya iniciado destinado a incrementar la transparencia del sector financiero y bancario, y se planteó la necesidad de adoptar medidas de regulación adicionales 
en los planos nacional e internacional, así como compromisos más rigurosos para garantizar su aplicación.

Una de las medidas fue la creación del Comité de Expertos Independientes,16 originalmente compuesto por ocho miembros, cuyo principal propósito era realizar un análisis objetivo de la plataforma de servicios de Panamá, con el fin de formular recomendaciones que pudieran ser incorporadas como mejores prácticas, para lograr los objetivos de transparencia exigidos por la comunidad internacional. Se otorgó al Comité un mandato general y se le pidió que mantuviera consultas con entidades públicas, privadas y multilaterales y que formulara recomendaciones. En agosto de 2016, cuatro meses después de la creación del Comité, dos de sus miembros más destacados, Joseph Stiglitz y Mark Pieth, decidieron abandonarlo, alegando que no se garantizaba la publicación inmediata del informe final que presentaría el Comité (Stiglitz y Pieth párr. 4).

Se han adoptado varias reformas y medidas financieras positivas, como la introducción de nuevos obstáculos para la emisión de acciones al portador, la obligación de que las empresas mantengan registros contables de las transacciones offshore, el reforzamiento de los requisitos de debida diligencia que deben cumplir los agentes residentes para identificar a los verdaderos dueños de los instrumentos societarios para los cuales proporcionan servicios, y la regulación y la supervisión de actores no financieros, tales como casinos, la Zona Libre de Colón, firmas de contadores y de abogados, e inmobiliarias, que tienen ahora la obligación de reportar las transacciones sospechosas.

En mayo de 2017, Panamá fue objeto de una evaluación del cumplimiento de las recomendaciones formuladas por el Grupo de Acción Financiera en 2012, que incluyó una visita local. La evaluación se centró en la aplicación efectiva del régimen de medidas de lucha contra el blanqueo de capitales y el financiamiento del terrorismo. El gobierno me informó que, después de la visita, el Grupo de Acción Financiera de Latinoamérica le transmitió el proyecto de informe de evaluación y que se espera que el informe final se publique en diciembre de 2017.

El 23 de febrero de 2017, Panamá depositó el instrumento de ratificación del Convenio de Asistencia Administrativa Mutua en Materia Fiscal, que aprobó mediante la Ley N. 5 de 2017.

El Convenio establece normas para el intercambio multilateral de información, previa solicitud, en materia fiscal y el intercambio automático de información de carácter bilateral, de conformidad con la declaración de políticas formulada por Panamá en materia de transparencia fiscal. ${ }^{17}$ Panamá intercambiará automáticamente información financiera únicamente con los países con los que tenga un acuerdo de autoridades competentes. El Convenio servirá de base jurídica para la negociación de acuerdos de autoridades competentes con las jurisdicciones asociadas y Panamá se compromete a negociar tales acuerdos con aquellas jurisdicciones extranjeras que 
dispongan de un marco jurídico y de sistemas tecnológicos adecuados para garantizar la confidencialidad y la protección de la información que se intercambie de manera automática. Cabe señalar que las reservas formuladas por Panamá en cuanto a la aplicación, en particular de parte de los artículos 2, 9, 17 y 28 del Convenio, implican que Panamá puede optar por no prestar asistencia a inspecciones fiscales del extranjero (EY Global Tax Alert 1).

Las negociaciones de acuerdos entre autoridades competentes para el intercambio automático de información se llevará a cabo en función de los intereses comunes y las normas internacionalmente aceptadas, por ejemplo las del Foro Global de la OCDE $\mathrm{u}$ otras jurisdicciones como México, el Reino Unido de Gran Bretaña e Irlanda del Norte y los Estados Unidos, que gozan de amplia experiencia en la evaluación de sistemas de protección de datos y confidencialidad.

Panamá ya ha firmado varios tratados de intercambio de información fiscal (Dirección General de Ingresos), entre otros con arreglo a la Foreign Account Tax Compliance Act (Ley de Cumplimiento Tributario de Cuentas Extranjeras) con los Estados Unidos, y está negociando el establecimiento de acuerdos bilaterales de intercambio de información fiscal con Colombia, Francia y Japón.

\section{Medidas adicionales necesarias}

Si bien ya ha mostrado su compromiso político de alcanzar un sistema financiero y fiscal más transparente, Panamá debería ampliar su enfoque para incluir los problemas omnipresentes de opacidad financiera y fiscal que se encuentran en el núcleo de las economías del siglo XXI.

Las razones por las que propugno esa evaluación global son múltiples: las infracciones fiscales en Panamá se consideran territoriales y solo conciernen a quienes residen en el país, lo que supone una gran limitación para combatir la evasión fiscal a través de las fronteras. Además, la evasión de impuestos se considera como infracción únicamente con arreglo al Código Fiscal de Panamá; no está regulada o penalizada como delito con arreglo al derecho penal. La defraudación fiscal está tipificada y se castiga con multa o, en algunos casos, con pena de prisión, pero no está castigada penalmente. La aplicación de esta disposición se ha delegado a una entidad administrativa dependiente del Ministerio de Economía y Finanzas, que investiga y juzga la contravención, y no a un fiscal o un juez (Código Fiscal arts. 752 y 1312).

Por consiguiente, quienes tienen la obligación de comunicar las transacciones sospechosas no necesitan fijarse especialmente en si sus clientes pagan o no impuestos. Más preocupante resulta el hecho de que el sistema de comunicación de "transacciones sospechosas" no parece abarcar el aspecto fiscal fundamental del más amplio problema de las corrientes financieras ilícitas: sus repercusiones en el bienestar de la mayoría de la población mundial. En otras palabras, el principio "conozca a su cliente" actualmente 
excluye el requisito de verificar que se respeten el estatus y las obligaciones fiscales en el país o en el extranjero. Es necesario cerrar esa brecha del ordenamiento jurídico panameño, y establecer una regulación y mecanismos de rendición de cuentas más sólidos. Las investigaciones penales que están en curso en el país contra aquellos que han creado, promovido, administrado y se han beneficiado del sistema amañado descubierto por los papeles de Panamá se han limitado a unos pocos abogados. Estos no son perseguidos por su rol en el sistema de facilitación de la defraudación fiscal y las actividades conexas en Panamá, sino por su presunto involucramiento en actividades de lavado de dinero junto con otros delitos cometidos en el extranjero. ${ }^{18}$

Naturalmente, soy consciente de que el establecimiento de sanciones penales para la evasión de impuestos debe ser parte de una estrategia integral. El fraude fiscal es un fenómeno complejo que afecta a todas las dimensiones relevantes de la economía, en especial a los sectores bancario, inmobiliario, los intermediarios financieros y no financieros, las firmas de contadores y abogados, y las zonas francas, tanto en las actividades internas como internacionales. No obstante, el sector financiero y bancario todavía ha de ser integrado de manera más directa y eficaz a la agenda de lucha contra los fondos ilícitos en Panamá. El sector de la intermediación financiera es próspero y representa aproximadamente un $7.7 \%$ del producto interno bruto (PIB), (Naciones Unidas 2017 párr. 141) con 90 bancos operativos, la mayoría de ellos con licencia para llevar a cabo operaciones tanto nacionales como internacionales. El Sistema Bancario Nacional informó que los activos aumentaron un 4 por ciento de 2015 a 2016. En 2016, el sector de la intermediación financiera creció un 6.6 por ciento, según las estimaciones del Instituto Nacional de Estadística y Censo (Ministerio de Economía y Finanzas, Dirección de Análisis Económica y Social 34).

Esas cifras obligan a evaluar detenidamente el papel que juegan las entidades bancarias y financieras en los flujos de dinero que los instrumentos societarios facilitan. Si bien es cierto que muchas transacciones financieras ejecutadas por compañías formalmente creadas en Panamá se llevan a cabo en jurisdicciones extranjeras, habida cuenta de que más del 40 por ciento de los activos financieros del sector financiero panameño son prestados en el extranjero, será absolutamente esencial que cualquier estrategia nacional orientada a reducir los fondos ilícitos incorpore al sector bancario. El Comité de Expertos Independientes creado por el gobierno presentó recomendaciones esenciales, que aún se están estudiando. No obstante, esas recomendaciones no bastarán si no se completan con medidas para asegurar mecanismos eficientes y sólidos de diligencia debida dentro del sector bancario.

La participación global de las entidades financieras en las estrategias abusivas de planificación fiscal para las empresas transnacionales en todo el mundo ha quedado confirmada por el creciente número de casos en que entidades financieras individuales recibieron sanciones específicas o fueron objeto de investigaciones por una serie de infracciones, siendo la más común ayudar a corporaciones y clientes 
adinerados a cometer fraudes fiscales (James). Muchos de los casos revelados en los papeles de Panamá apuntan en esa dirección.

Aliento a la Superintendencia de Bancos a que amplíe el alcance y la naturaleza de la información disponible públicamente, ofreciendo el expediente completo, incluidas las investigaciones y sanciones impuestas a las entidades que supervisa, así como las razones de tales investigaciones y sanciones. Este paso también puede aumentar la confianza en la rendición de cuentas de todos los actores, independientemente de su posición económica.

Panamá necesita fortalecer la dimensión fiscal de la diligencia debida, especialmente en el sector bancario: más allá del volumen real del impuesto evadido al Estado panameño -dado el principio de territorialidad en que se basa su sistema tributarioexisten obligaciones extraterritoriales de no propiciar impactos fiscales negativos en otras jurisdicciones. Además, los costos de reputación derivados de los "papeles de Panamá" también deben conducir a un debate nacional acerca del tipo de inversión que conviene atraer al país y con qué propósito. ${ }^{19} \mathrm{El}$ informe del Comité de Expertos Independientes ha planteado cuestiones similares en relación con la erosión de la base imponible, la transferencia de utilidades y la inversión de capital.

Asimismo, para implementar efectivamente las reformas encaminadas a mejorar la transparencia fiscal y financiera en el país, es preciso fortalecer la gobernanza. Debe establecerse una legislación clara y sólida sobre los conflictos de intereses para asegurar la autonomía y la independencia de los reguladores y supervisores sectoriales y de los responsables de la toma de decisiones. Si bien se me informó que el Congreso había debatido un proyecto de ley para regular ese aspecto, la legislación debería garantizar la inclusión efectiva de los principios pertinentes aplicables en ese ámbito, como la separación de poderes, la legalidad, la publicidad de los actos administrativos, la imparcialidad y la eficiencia.

\section{Crecimiento económico, desigualdad y derechos humanos}

Desde la perspectiva de los derechos humanos, un crecimiento económico que no va acompañado de progresos sustanciales hacia la igualdad es un claro indicio de la necesidad de leyes, políticas y programas más eficaces y mejor concebidos. El constante crecimiento económico en un país con un sector financiero y bancario de importancia mundial y una floreciente plataforma de servicios debería traer consigo esfuerzos concertados para reducir las desigualdades económicas, sociales y políticas, superar la pobreza y la marginación y lograr rápidamente el pleno ejercicio de los derechos económicos, sociales y culturales de todos los residentes, en particular los grupos de población más necesitados.

En ese contexto, es preciso tener presentes varios indicadores sociales y demográficos fundamentales. Con una población de unos 4580000 habitantes en 2016 
(Naciones Unidas 2017 párr. 4), y una disminución de la tasa de crecimiento demográfico a alrededor del $1.55 \%$ anual, el gobierno reconoce correctamente que tiene una valiosa oportunidad de afrontar la pobreza y las desigualdades regionales (Naciones Unidas 2017 párr. 12). La población de Panamá es principalmente urbana, con una proporción del 65.1 por ciento de habitantes en las ciudades (Naciones Unidas 2017 párr. 71), sobre todo en Panamá y Colón. Alrededor del 60.2 por ciento de los hogares monoparentales tienen a una mujer como cabeza de familia, lo que indica que las estrategias de reducción de la pobreza deben orientarse a las mujeres como grupo prioritario (Naciones Unidas 2017 párr. 72).

En marzo de 2016, el 9.9 por ciento de la población, esto es unas 450000 personas, vivía en la pobreza extrema o no disponía de ingresos suficientes para cubrir sus necesidades nutricionales mínimas (Naciones Unidas 2017 párr. 88 y Ministerio de Economía y Finanzas 85), mientras que el 22.1 por ciento de la población vivía en la pobreza "general" (Naciones Unidas 2017 párr. 88 y Ministerio de Economía y Finanzas 85). ${ }^{20}$

En términos absolutos, el crecimiento ha llevado a la reducción de la pobreza, en especial desde 2004. Entre 2001 y 2016, hubo una reducción significativa de la tasa de desempleo, que pasó del 14 por ciento al 5.5 por ciento (Naciones Unidas 2017 párr.126). Algunas cifras netas positivas muestran el aumento considerable del gasto público en el sector social en relación con el gasto total, del 44.3 por ciento en 2000 al 59.1 por ciento en 2015 (Naciones Unidas 2017 párr. 164). En 2015, la mayor proporción del gasto social total (el $36.3 \%$ ) correspondió al sector de la salud, tomando en cuenta la inversión realizada en programas de suministro de agua potable y saneamiento básico (Naciones Unidas 2017 párr.166). La menor asignación fue la destinada a vivienda, con solo el 2.7 por ciento de la inversión pública (Naciones Unidas 2017 párr. 170).

Entre 2008 y 2016, los datos indican una reducción constante tanto de la pobreza general como de la pobreza extrema, aunque no fue proporcional a la expansión económica. Más preocupante resulta la persistencia de las desigualdades: en 2016, alrededor del 2.8 por ciento de la población urbana vivía en la pobreza extrema, mientras que la cifra correspondiente a la población rural era del 24.8 por ciento, nueve veces mayor. Las cifras de 2016 relativas a la pobreza general también son sorprendentes: en las zonas urbanas la tasa era del 11.1 por ciento, mientras que en las rurales era del 45.2 por ciento, cuatro veces mayor (Ministerio de Economía y Finanzas 85).

La pobreza afecta de manera desproporcionada a la población indígena, que solo supone el 12.3 por ciento de la población total, unos 418000 habitantes. Los principales grupos son: Ngäbe (el 62.3 por ciento de la población indígena), Kuna (el 19.3 por ciento) y Emberá (el 7.5 \%) (Naciones Unidas 2017 párr. 22). Todavía hay altos índices de pobreza en las comarcas indígenas y en aquellas provincias con una mayor proporción de personas que residen en áreas rurales de difícil acceso o con presencia de comunidades indígenas (Naciones Unidas 2017 párr. 80). En las comarcas indígenas, 
la pobreza supera el $70 \%$ y la extrema pobreza llega al $40 \%$, cuatro veces el promedio nacional. En ese contexto, el Plan de Desarrollo Integral de los Pueblos Indígenas de Panamá debería aplicarse de conformidad con las normas y principios internacionales de derechos humanos relativos a los derechos de los pueblos indígenas.

Panamá se enorgullece de la fortaleza de su modelo económico orientado a los servicios ${ }^{21}$ y del impresionante crecimiento con un promedio anual del $7.9 \%$ que logró entre 2011 y 2015 (Naciones Unidas 2017 párr. 145), que representa más del doble que el promedio de América Latina y el Caribe y figura entre los más altos del mundo durante el mismo período. Ese crecimiento se ha visto propiciado por el hecho de que la administración del Canal de Panamá pasó a manos nacionales. El país se beneficia de su ventaja geográfica como centro de servicios bancarios y financieros, logísticos, de transporte y comunicaciones. La Comisión Económica para América Latina y el Caribe (CEPAL) estima que Panamá tendrá en 2017 un crecimiento económico del 5.9\%, tres veces mayor que el del resto de la región (Ministerio de Economía y Finanzas 55). Para los años siguientes se estima que será de una media de entre el $3.8 \%$ y el $5.3 \% .^{22}$

Según el Global Competitiveness Report 2016-2017, Panamá protagonizó la mayor progresión en el índice de competitividad mundial durante ese período, y estuvo a la cabeza en la región en cuanto a entorno macroeconómico, eficiencia del mercado de bienes, el desarrollo del mercado financiero y sofisticación empresarial. Ascendió de la 50. a posición en 2015-2016 a la 42. a posición en 2016-2017 (Schwab 20).

Ese panorama tan positivo en cuanto a crecimiento y competitividad no se condice con unos indicadores críticos desde la perspectiva de los derechos humanos. De hecho, resulta muy problemático observar unos niveles de crecimiento elevados al mismo tiempo que una desigualdad persistente. En 2015, el coeficiente de ingreso de Gini era más alto en Panamá que en muchos países de la región, con un valor de 0.48 (Naciones Unidas 2017 párr. 91). Se podría caer en la trampa de considerar que se trata de una simple paradoja que se corregirá con el tiempo, si no fuera por el análisis de las opciones políticas y económicas que parecen seguir favoreciendo la consolidación de las riquezas y el crecimiento en manos de unos pocos. Vale la pena señalar que Panamá tiene una de las proporciones más bajas de impuestos en relación con el PIB en la región de América Latina, que en 2015 era del 16.2 por ciento frente al promedio regional del 22.5 por ciento. Si bien todos los países de la región aumentaron esa proporción entre 1990 y 2015, en Panamá ha seguido siendo prácticamente la misma (OCDE, CEPAL, Centro Internacional de Agricultura Tropical y Banco Interamericano de Desarrollo 45). Ello podría explicarse por diversos factores, como las políticas que no siempre están orientadas a eliminar los aspectos estructurales y sistémicos que mantienen las desigualdades, especialmente la persistencia de la exclusión y la discriminación en contra de algunos sectores de la población y algunas regiones del país.

En el Plan Estratégico de Gobierno 2015-2019 se reconoce que el desarrollo reciente se ha producido sobre la base de una estructura social, económica e institucional 
que arrastra múltiples desequilibrios y carencias. Asimismo, se señala como objetivo explícito la mejora de la inclusión social. Además, en opinión de este, la falta de equilibrios y las brechas en los impuestos impiden distribuir la riqueza de manera amplia para crear una sociedad más inclusiva, justa y productiva.

La política fiscal es una herramienta poderosa que los gobiernos pueden utilizar para abordar la exclusión y la desigualdad, y para asegurar que ningún grupo acapare los beneficios del crecimiento. Más importante aún, los impuestos deben también ser entendidos como un elemento esencial para el cumplimiento de las obligaciones internacionales de derechos humanos, notablemente para equilibrar desigualdades. Por ejemplo, en el contexto del rápido crecimiento de los inmuebles y las propiedades horizontales de alta gama, especialmente en la Ciudad de Panamá, se está llevando a cabo un debate legislativo acerca de la reducción del impuesto a las propiedades. Mientras algunas constructoras han expresado que el gravamen actual es muy alto y que el avalúo es muy "subjetivo", el gobierno considera justamente que dejar de aplicar este impuesto sería perjudicial para la base imponible global. Desde 2010, la construcción, incluida la residencial, ha sido la actividad económica que más ha contribuido al PIB total del país, debido al aumento de la inversión en infraestructuras públicas y privadas, incluida la construcción residencial (Naciones Unidas 2017 párrs. 142-146).

El presupuesto nacional debe ser racionalizado, con una mejor inversión pública planificada y regulada en las áreas sociales, la cual es dramáticamente necesaria en especial en las áreas pobres y marginadas y en las comunidades rurales, indígenas y urbanas pobres. Las ventajas económicas de Panamá deberían estar orientadas a beneficiar a su pueblo. En la planificación presupuestaria y la programación deben considerarse necesidades plurianuales, mecanismos de rendición de cuentas y balances actualizados de los tipos de inversiones que permitan asegurar la reducción de la inequidad como prioridad máxima.

En agosto de 2017, el gobierno presentó su Plan Estratégico Nacional 2030, que tiene como objetivo aunar la visión y las prioridades políticas nacionales con la Agenda 2030 para el Desarrollo Sostenible. El Plan define la visión de Panamá en 2030 como un Estado con alto desarrollo humano, económico, social y tecnológico, con justicia, inclusión, igualdad de oportunidades e interculturalidad y recursos naturales sostenibles. La base en la que reposan los Objetivos de Desarrollo Sostenible es el disfrute de todos los derechos humanos sin discriminación, y la promesa de que nadie se quedará atrás se orienta claramente hacia ámbitos en los que Panamá puede lograr progresos sustanciales.

Elogio a Panamá por haber sido el primer país de la región en elaborar un plan de acción acorde con los Objetivos de Desarrollo Sostenible y pide al gobierno en particular que haga todo lo posible por que el Objetivo 10 y su claro llamamiento basado en los derechos humanos de reducir la desigualdad forme parte esencial de la 
aplicación de su Plan Estratégico. Concretamente, subrayo que entre las metas previstas en el Objetivo 10 están las de aprobar políticas, especialmente fiscales, salariales y de protección, mejorar la reglamentación y vigilancia de las instituciones y los mercados financieros mundiales y fortalecer la aplicación de esos reglamentos.

\section{Proyectos de infraestructura y derechos humanos}

Otra dimensión crítica de la evaluación del crecimiento económico a la luz de los derechos humanos es la atención prestada a las inversiones y proyectos de infraestructura y agroindustria, a menudo cofinanciados por bancos multilaterales de desarrollo e instituciones financieras privadas. La capacidad económica de Panamá, el fácil acceso al crédito y su prioridad en la prestación de servicios a los mercados internacionales, han dado un énfasis sin igual a una serie de proyectos sin que antes de realizarlos se llevaran a cabo evaluaciones completas de sus efectos en los derechos humanos e impacto ambiental. Por ejemplo, fui informado de las consecuencias de las centrales hidroeléctricas en la provincia de Chiriquí, en particular las conocidas como "La Cuchilla", "Chuspa" y "Chan 75". En algunos de estos casos, el volumen de agua utilizada, el tipo de contratos de concesión con empresas y el impacto en el caudal de los ríos en estas áreas sugieren no solo un impacto directo en la falta de acceso al agua para uso doméstico y personal, sino también un impacto ambiental a largo plazo en las vías fluviales, los ecosistemas y las condiciones humanas de comunidades enteras. También recibió información referente al desplazamiento de población causado por conflictos de tierras y ventas ilícitas en el caso de Kusapín, y al desplazamiento de afrodescendientes debido a un proyecto turístico en Pedro González.

En relación con los proyectos de infraestructura, también se planteó la compleja situación de la planta hidroeléctrica de Barro Blanco que se debatió con funcionarios públicos y organizaciones de la sociedad civil. Durante años, diversas cuestiones relativas a la planta fueron un tema de preocupación considerado por varias instancias nacionales, así como por la Comisión Interamericana de Derechos Humanos, además de haber sido objeto de un llamamiento urgente de varios titulares de procedimientos especiales en junio de $2016 .{ }^{23} \mathrm{El}$ gobierno respondió señalando la importancia que le otorga al diálogo y la resolución pacífica de los conflictos, así como su compromiso proactivo para asegurar que un acuerdo reciente con las comunidades fuera alcanzado de manera participativa y que fuera implementado. Se ha observado que, a medida que se aproxima la finalización de este proyecto, existe un aspecto esencial de reparación y compensación. En otros casos, antes de que cualquier proyecto sea desarrollado, es preciso garantizar los estándares de derechos humanos en materia de consentimiento libre, previo e informado, que deben respetar tanto los gobiernos como los financiadores públicos y privados. 
En este campo, el Estado está obligado por el derecho internacional de los derechos humanos, que protege de manera especial a los grupos más vulnerables, y por los tratados bilaterales de inversión, que protegen los derechos de los inversionistas. ${ }^{24}$

También fui informado de que el Decreto Ejecutivo N. 62 de 30 de marzo de 2017 reglamentó el conjunto de los organismos sin fines de lucro, con el fin de abordar, entre otras cosas, las preocupaciones acerca de los posibles vínculos con la financiación cuestionable de partidos políticos. No obstante, según algunos organismos, el Decreto resulta excesivamente ambiguo en algunos aspectos y crea poder discrecional en cuanto a la regulación de organismos centrados específicamente en la protección y la promoción de los derechos humanos o de asociaciones de defensa de los derechos de comunidades en el ámbito de los proyectos de infraestructuras. La consecuencia, aunque involuntaria, sería una reducción del espacio cívico esencial para la labor de defensa de los derechos humanos. ${ }^{25}$ Quisiera subrayar que la libertad de asociación y de expresión, así como la indispensable labor de los defensores de los derechos humanos deben ser protegidas, y que los decretos o regulaciones que el Estado imponga a las organizaciones de la sociedad civil que se ocupan de los derechos humanos no deben limitar ni reducir la capacidad de estas para supervisar y promover sus asuntos de interés legítimos, lo que ayuda a fortalecer los mecanismos e instituciones democráticos. La regulación tendente a incrementar la transparencia de la financiación de los partidos políticos es importante. No obstante, las medidas no deben ser tan generales que tengan consecuencias negativas en el espacio cívico para ejercer la labor de defensa de los derechos humanos.

\section{Conclusiones}

No cabe duda de que la transparencia financiera y fiscal es un objetivo central en todo el mundo. Si se ignoran la interrelación entre las dimensiones nacional e internacional y las implicaciones de las corrientes financieras ilícitas al evaluar la situación de un país se obtendrá un resultado incompleto. Panamá puede y debe seguir haciendo cuanto esté de su parte para fortalecer su enfoque global de la transparencia, como deberían hacer los demás países.

Los cambios regulatorios nacionales e internacionales que se vieron acelerados por los llamados "papeles de Panamá" han puesto de manifiesto que Panamá se esfuerza por incrementar la transparencia y la rendición de cuentas dentro de su plataforma de servicios financieros. Ahora bien, dado que una agenda de transparencia anclada en el derecho internacional de los derechos humanos ha de ser eficaz igualmente desde el punto de vista fiscal, es preciso que las entidades financieras y no financieras, así como los profesionales que participan en actividades objeto de supervisión, sean considerados partes interesadas fundamentales en los esfuerzos del gobierno por combatir la evasión y el fraude fiscal. Si la evasión de impuestos, 
el fraude fiscal y la asistencia prestada para esos fines, en ciertas circunstancias graves, se consideraran constitutivos de delito, los intermediarios financieros y los profesionales del sector financiero tendrían la obligación de reportar las transacciones sospechosas desde el punto de vista tributario. Además, deberían rendir cuentas si no cumplieran ese requisito.

Concretamente, es preciso establecer regulaciones bancarias más robustas, incluidos procesos de diligencia debida más estrictos y sistemáticos, de manera que las entidades anteriormente mencionadas contribuyan a impedir la práctica de la evasión y elusión fiscal por personas nacionales y extranjeras, entidades jurídicas u otros mecanismos legales, de conformidad con los controles más estrictos que se están adoptando en el sector bancario de varias jurisdicciones. Soy consciente de los retos que ello puede suponer, pero está convencido de que seguir retrasando el aumento de los controles será perjudicial a largo plazo, y de que Panamá actualmente está en buenas condiciones de lograr cambios estructurales, y al mismo tiempo seguir manteniendo la competitividad, la eficacia y la plena transparencia.

Como indicó un experto en cuestiones de transparencia de Panamá, contrariamente a la idea establecida, los "papeles de Panamá" no disuadieron a los depositantes de los bancos que operan en Panamá. Según la Superintendencia Bancaria, los activos totales del centro bancario, en noviembre de 2016 ascendían a 119000 millones de dólares, un 1.7 por ciento más que en marzo de 2016, antes del incidente de los "papeles de Panamá" (Barsallo párr. 9). Ello suscita la cuestión sobre si la agenda de transparencia ha sido ineficaz o, por el contrario, si el aumento de la transparencia consolidaría en la práctica la plataforma financiera de Panamá. En cualquier caso, parece ser el buen momento para profundizar la transparencia financiera en Panamá.

Panamá debería promover una sólida agenda en materia de transparencia, no solo en el plano nacional, sino en los foros bilaterales y multilaterales para garantizar que su sector de servicios bancarios y financieros no afronte la competencia desleal de agentes estatales y no estatales que siguen siendo reacios a aceptar las medidas destinadas a garantizar la justicia tributaria mundial. Todos los Estados deberían aplicar regulaciones claras que hagan ilícito declarar de manera intencionada, incorrecta o inexacta el precio, la cantidad, la calidad $u$ otros aspectos del comercio de bienes y servicios a fin de trasladar capital o beneficios a otra jurisdicción o manipular, evadir o evitar cualquier tipo de gravamen. Debería asegurarse una genuina reciprocidad y buena fe por parte de todos los países en el cumplimiento de los tratados de intercambio de información fiscal, al igual que la asistencia a los Estados en desarrollo que pueden estar mal preparados para participar en pie de igualdad en el sistema de intercambio automático de información.

No obstante, quisiera subrayar que la mejora de la transparencia fiscal y financiera en Panamá ha de entenderse y abordarse también como una vía hacia el cumplimiento de las obligaciones internacionales en materia de derechos humanos. 
En otras palabras, las medidas y las políticas en el ámbito económico, financiero y fiscal deberían figurar de manera expresa y destacada entre los componentes de la visión y la estrategia nacional en materia de derechos humanos. El crecimiento económico continuado debe aprovecharse para mejorar las condiciones de vida de todos. Debería haber mecanismos eficaces que garanticen que el crecimiento cumpla un papel en la reducción de la desigualdad socioeconómica que experimentan los pobres de las zonas urbanas y rurales, y los pueblos indígenas. Además, es preciso luchar firmemente contra la desigualdad, en particular implantando las reformas fiscales necesarias, así como regulaciones y políticas para el sector financiero. Panamá debe cerciorarse de que sus esfuerzos se orienten en primer lugar al desarrollo humano y la efectividad de los derechos humanos, y que su próspera plataforma de servicios contribuya a conseguir ese objetivo general.

Panamá ha tenido una de las tasas de crecimiento económico más elevadas del mundo durante el último decenio y ha progresado de manera constante en la reducción de la pobreza general. Sin embargo, persisten desigualdades sistémicas y preocupantes, en particular en relación con la población de zonas rurales, los pueblos indígenas y los pobres de zonas urbanas que siguen afrontando la pobreza extrema. Los períodos de bonanza económica y un sector financiero próspero deberían considerarse una oportunidad única para que el país vele por que los cambios estructurales, especialmente de sus políticas fiscales, así como las inversiones sociales de largo plazo y debidamente orientadas ocupen un primer plano, con un programa concertado para distintos sectores a fin de asegurar la efectividad de los derechos económicos, sociales y culturales de todos.

Los proyectos de infraestructuras a menudo afectan directamente a los derechos humanos de las comunidades y los pueblos indígenas, al provocar el desplazamiento, la indigencia y privarlos de acceso a una vivienda adecuada, alimentos, vías fluviales o tierras ancestrales. Si no se mantienen consultas ni se obtienen la participación y el consentimiento previo informado, esos proyectos ocasionarán graves violaciones de los derechos humanos, o situaciones que podrían haberse evitado, que a menudo afectan a los pobres y desatendidos. Panamá está realizando una serie de proyectos de infraestructura y la inversión pública y privada en ese ámbito está en alza. Si se llevan a cabo sin evaluar debidamente su impacto en los derechos humanos y sin asegurar una verdadera participación de las personas afectadas, incluido el consentimiento previo e informado de los pueblos indígenas, los proyectos podrían desencadenar tensiones sociales o inestabilidad en los próximos años y aumentar el riesgo de que se cometan abusos contra los derechos humanos.

Vale la pena señalar que aquellas personas que no se benefician de la plataforma de servicios financieros en Panamá ni oponen resistencias a una mayor transparencia en dicho sector suelen pertenecer a los grupos más vulnerables de la sociedad, 
quienes padecen de las desigualdades socio-económicas existentes en el país y, en no pocas oportunidades, los efectos adversos de los proyectos de infraestructura. Es por ello que, como lo sugiere el título de este artículo, es necesaria la evocación amplia y consistente de los derechos humanos para abordar los problemas de la economía y las finanzas en el país (y en el mundo entero).

\section{Recomendaciones para fortalecer el debate}

Habida cuenta de los efectos adversos para los derechos humanos que tienen a nivel mundial las corrientes financieras ilícitas, las cuales a menudo privan a los Estados de recursos indispensables para garantizar la efectividad de los derechos humanos, se subrayan seguidamente las recomendaciones generales que son aplicables a todos los países y jurisdicciones (incluida Panamá), así como las recomendaciones específicas que debe considerar únicamente Panamá.

Los Estados, los bancos, las aseguradoras, las empresas transnacionales y las firmas de contadores y abogados pueden contribuir a incrementar la transparencia en el plano mundial si aplican las cuatro grandes recomendaciones siguientes:

a) Eliminar las compañías ficticias y las cuentas anónimas, imponiendo el requisito legal de declarar públicamente toda la información del beneficiario final de todas las entidades comerciales, entre ellas, sociedades, fideicomisos, fundaciones y entidades benéficas, creadas en su jurisdicción.

b) Intensificar la participación en las conversaciones y las iniciativas con miras a lograr el intercambio automático de información fiscal a nivel mundial.

c) Considerar y poner en marcha iniciativas orientadas al establecimiento de un mandato legal de presentación de informes públicos país por país por parte de las corporaciones transnacionales, en los que figuren sus activos, ingresos, utilidades, impuestos pagados y número de empleados, como también su balance de situación en cada una de las jurisdicciones donde operan, en vez de presentar un balance global consolidado. ${ }^{26}$

d) A fin de restringir la manipulación de los precios de transferencia, utilizar una clara referencia de precios de los productos básicos cotizados públicamente, en las transacciones con esos productos, especialmente en las que se realizan entre partes vinculadas. Se debería crear una base de datos internacional y pública de precios comparables y fiables, que permitiría a las autoridades fiscales, especialmente de los países en desarrollo, estar en mejores condiciones para afrontar posibles abusos en este ámbito (Conferencia de las Naciones Unidas sobre Comercio y Desarrollo 218). 
A su vez, se recomienda que Panamá introduzca las siguientes medidas específicas:

a) Hacer que la evasión fiscal y la asistencia a la evasión fiscal sea delito con arreglo al Código Penal, no una mera infracción administrativa o fiscal.

b) Añadir el fraude fiscal a la lista de las transacciones sospechosas que las entidades financieras y no financieras deben comunicar a las autoridades competentes.

c) Establecer mecanismos de diligencia debida claros y robustos para el sector bancario con el fin de disuadir a los clientes de los bancos de emprender actividades que vulneren la legislación tributaria y poner esas vulneraciones en conocimiento de las autoridades competentes. En particular, los bancos pueden y deben contribuir a impedir la evasión y la elusión fiscal en el ámbito nacional e internacional.

d) Promulgar una legislación mejorada que asegure la plena autonomía e independencia de los reguladores y supervisores sectoriales y los responsables de la toma de decisiones en materia fiscal y financiera.

e) Velar por que el regulador bancario amplíe el alcance y la naturaleza de la información disponible públicamente acerca de las investigaciones y sanciones impuestas a las entidades que supervisa, así como las razones de tales investigaciones y sanciones.

f) Firmar nuevos tratados bilaterales de intercambio de información fiscal que cubran todos los países con los que Panamá mantiene relaciones comerciales significativas.

g) Aumentar los controles efectivos de las firmas de contadores, algunas de las cuales pueden ocultar deliberadamente los vínculos entre oficinas o personal de distintas jurisdicciones con el fin de "proteger" a sus clientes de las investigaciones de los reguladores y los riesgos legales.

h) Adoptar medidas efectivas para asegurar unas políticas fiscales progresivas y racionalizar el presupuesto, tanto en cuanto a ingresos como a resultados e inversiones, con el fin de reducir las desigualdades socioeconómicas y la pobreza y velar por la redistribución de las ganancias derivadas del crecimiento económico.

i) Realizar todos los proyectos de infraestructuras con el consentimiento previo e informado de los pueblos indígenas u otras comunidades que puedan resultar directamente afectadas, y velar por que las personas afectadas puedan participar verdaderamente en el proceso decisorio, basándose en información adecuada y oportuna. 
j) Hacer que los tratados bilaterales en materia de inversión y la inversión extranjera directa en el país estén sujetos a evaluaciones de impacto social y ambiental antes de su aprobación o ratificación.

k) Ofrecer compensación a las comunidades que ya se han visto perjudicadas por proyectos de infraestructura y velar por que reciban reparación acorde con los derechos humanos.

1) Presentar los informes pendientes a los mecanismos de supervisión de los órganos de tratados, en particular el tercer informe periódico que debía haberse presentado en 2004 al Comité de Derechos Económicos, Sociales y Culturales.

\section{Notas}

$1 \quad$ El autor agradece a Frederique Bourque, Juana Sotomayor y Gunnar Theissen de la Oficina del Alto Comisionado por los Derechos Humanos por su dedicación y compromiso durante el trabajo de investigación y editorial del informe de misión a Panamá sobre el cual se basa este artículo.

El autor, en su carácter de Experto Independiente en Deuda Externa y Derechos Humanos de la Organización de las Naciones Unidas, realizó del 2 al 10 de mayo de 2017 una visita oficial a Panamá. El propósito de la visita fue examinar la aplicación en el ámbito económico, financiero y fiscal de los principios y las normas internacionales en materia de derechos humanos en el por medio de la legislación, las políticas y los programas, de conformidad con lo dispuesto en las resoluciones 34/3 y 31/11 del Consejo de Derechos Humanos. El informe de misión, sobre el cual se basa este artículo, fue presentado al Consejo el 28 de febrero de 2018. La visita se centró en tres esferas principales y en ofrecer al gobierno recomendaciones útiles y constructivas. Las tres esferas fueron: a) las políticas financieras y fiscales establecidas con el fin de incrementar la transparencia y reducir los abusos fiscales y las corrientes financieras ilícitas; b) la medida en que los beneficios del crecimiento económico se habían traducido en mejoras del goce de los derechos humanos, sobre todo los derechos económicos, sociales y culturales de los residentes en Panamá; y c) la posibilidad de que los proyectos de infraestructuras tuvieran efectos adversos en el goce de los derechos humanos de las personas y los grupos, incluidos los pueblos indígenas. El propósito de divulgar las ideas y propuestas elaboradas en dicho informe frente a una audiencia académica como la que ofrece el Anuario de Estudios Centroamericanos, reside en la intención de fomentar el diálogo abierto y el aprendizaje mutuo en cuestiones tan complejas como las analizadas en este trabajo.

3 La facturación comercial fraudulenta y las pérdidas tributarias que ocasiona son elementos importantes de las corrientes financieras ilícitas mundiales y contribuyen a la desigualdad en todo el mundo, especialmente en los países en desarrollo. Es posible consultar estimaciones de la magnitud de esas corrientes en www.gfintegrity.org/report/illicit-financial-flows-to-andfrom-developing-countries-2005-2014/

Panamá ratificó el Pacto Internacional de Derechos Económicos, Sociales y Culturales y el Pacto Internacional de Derechos Civiles y Políticos el 8 de marzo de 1977; la Convención Internacional sobre la Eliminación de Todas las Formas de Discriminación Racial el 16 de agosto de 1967; la Convención sobre la Eliminación de Todas las Formas de Discriminación contra la Mujer el 29 de octubre de 1981; la Convención sobre los Derechos del Niño el 12 de 
diciembre de 1990; y la Convención sobre los Derechos de las Personas con Discapacidad el 7 de agosto de 2007.

Panamá ratificó la Convención Americana sobre Derechos Humanos el 8 de agosto de 1978 y su Protocolo Adicional el 28 de octubre de 1992.

Véase la observación general núm. 3 (1990) del Comité de Derechos Económicos, Sociales y Culturales, sobre la índole de las obligaciones de los Estados partes.

Véase A/HRC/20/23, anexo. Suscritos por el Consejo de Derechos Humanos mediante su resolución 20/10.

Véase A/HRC/17/31, anexo. El Consejo de Derechos Humanos los hizo suyos en su resolución 17/4.

Como referencia de las normas internacionales pertinentes, véanse los Principios de Maastricht sobre las Obligaciones Extraterritoriales de los Estados en el Área de los Derechos Económicos, Sociales y Culturales (2011). Además, en sus observaciones finales relativas a los informes de Suiza, de 2016, el Comité para la Eliminación de la Discriminación contra la Mujer interpretó la afirmación de que los Estados tienen obligaciones extraterritoriales en lo que respecta al secreto financiero y las corrientes financieras ilícitas (véase CEDAW/C/CHE/CO/4-5 y Corr.1, párr. 41 a).

Aprobada mediante el Decreto de Gabinete núm. 238 de 2 de julio de 1970.

El dólar de los Estados Unidos tiene curso legal en Panamá desde 1904 y el balboa tiene un valor a la par del dólar.

Aprobada por el Decreto Ley N. 9, de 26 de febrero de 1998.

Panamá aún no ha ratificado la Convención para Combatir el Cohecho de Servidores Públicos Extranjeros en Transacciones Comerciales Internacionales, de la OCDE.

En una carta de fecha 1 de septiembre de 2017, el gobierno me indicó que el Fondo Monetario Internacional había incluido a Panamá en la "lista gris", en parte porque el país solo estaba cumpliendo plenamente una de las recomendaciones formuladas por el Grupo de Acción Financiera. Además, una de las deficiencias más importantes residía en la falta de un marco normativo completo, ya que existían sectores no regulados, como el de las aseguradoras, el arrendamiento financiero, la factorización, el comercio de piedras preciosas, la contabilidad, las notarías y los bufetes de abogados, así como en el hecho de que Panamá no cooperaba como era debido a nivel internacional.

OCDE, Global Forum on Transparency and Exchange of Information for Tax Purposes, págs. 14 y 15.

Creado en virtud del Decreto Ejecutivo núm. 94 de 29 de abril de 2016. Véase el informe final del Comité, de fecha 18 de noviembre de 2016. Puede consultarse en https://www.presidencia.gob.pa/

El Decreto Ejecutivo núm. 10 de 2 de febrero de 2017, por el que se adoptó la política de cumplimiento del país en relación con la transparencia fiscal y se establecieron los criterios de acuerdo con los cuales la República de Panamá entrará en relaciones de intercambio automático de información para fines fiscales.

Véanse las referencias a la extensa operación del Ministerio Público Federal del Brasil, denominada "Lava Jato", que está considerada como el mayor caso de corrupción investigado 
en el país y que presenta amplias ramificaciones en varios países de América Latina. Pueden consultarse en www.mpf.mp.br/para-o-cidadao/caso-lava-jato/entenda-o-caso

19 Estas definiciones políticas fundamentales se relacionan con los estudios de cientistas sociales como Julio Manduley, quien ya en los setenta planteaba interrogantes acerca de la sostenibilidad social, política y económica de una sociedad que se erigiera como enclave bancario-financiero internacional, su relación con el subdesarrollo y el imperialismo económico, en "El proceso panameño", Cuadernos Políticos, № 15, México, D.F., Editorial Era, enero-marzo de 1978, pp. 62-74. En esa misma línea de razonamiento ver también Xabier Gorstiaga, “La inversión extranjera en Panamá y su impacto en la estructura económica del país", en Susana Bodenheimer et al. "La inversión extranjera en Centroamérica", Editorial Universitaria Centroamericana, Costa Rica, 1974 y 1981, pp. 289-346.

Las referencias a la pobreza "extrema" y "general" corresponden a las medidas realizadas por el gobierno de Panamá. En el informe no se facilita una definición de la pobreza "general".

21 Como referencia, el 83\% del PIB en 2015 provino de los servicios (logística y transporte, banca, seguros, telecomunicaciones).

Véase The Economist Intelligence Unit, Panama Forecast, 1 de septiembre de 2017.

23 Llamamiento urgente conjunto del Relator Especial sobre los derechos humanos y el medio ambiente y la Relatora Especial sobre los derechos de los pueblos indígenas (ref.: UA PAN 1/2016, de fecha 23 de junio de 2016). Respuesta del gobierno de Panamá de fecha 5 de agosto de 2016. Ambos documentos están disponibles en https://spcommreports.ohchr.org

A título de referencia, véase Corte Interamericana de Derechos Humanos, Caso Comunidad Indígena Sawhoyamaxa vs. Paraguay, 29 de marzo de 2006.

Comunicación conjunta del Relator Especial sobre la promoción y protección del derecho a la libertad de opinión y de expresión, el Relator Especial sobre los derechos a la libertad de reunión pacífica y de asociación, y el Relator Especial sobre la situación de los defensores de los derechos humanos (ref.: OL/PAN/1/2017, de fecha 22 de mayo de 2017). Respuesta del gobierno de Panamá de fecha 25 de julio de 2017. Ambos documentos están disponibles en https:// spcommreports.ohchr.org/

Véase un análisis detallado en James Henry, "Let's tax anonymous wealth!" en Global Tax Fairness.

\section{Bibliografía}

Alstadsaeter, Annette Johannesen, Niels y Zucman, Gabriel, Tax evasion and inequality. 28 de mayo de 2017. Recuperado de www.nielsjohannesen.net/wp-content/uploads/ AJZ2017.pdf

Barsallo, Carlos "Panama's reputation: rising again from the embers", ICSA The Governance Institute. 24 de agosto de 2017. Recuperado de www.icsa.org.uk/knowledge/governance-and-compliance/features/will-panamas-reputation-rise-again-from-the-embers

Comisión Económica para América Latina y el Caribe. Ranking de puertos. Los Top 20 en América Latina y el Caribe en 2016. Infografía. CEPAL, 06 de junio de 2017. Recuperado de https:// www.cepal.org/es/infografias/ranking-puertos-top-20-america-latina-caribe-2016 
Conferencia de las Naciones Unidas sobre Comercio y Desarrollo, Informe sobre el Comercio y el Desarrollo 2014. Nueva York y Ginebra: Naciones Unidas, 2014.

EY Global Tax Alert. Panama issues policy statement regarding its compliance with fiscal transparency. 14 de febrero de 2017. Recuperado de www.ey.com/gl/en/services/tax/international-tax/alert--panama-issues-policy-statement-regarding-its-compliance-withfiscal-transparency

Georgia Tech Panama. Logistic Innovation \& Research Center. Zonas Francas. Panamá: Georgia Tech, 2018. Recuperado de https://logistics.gatech.pa/es/assets/special-economic-zones/free-zones

Gobierno de la República de Panamá. Plan Estratégico de Gobierno 2015-2019. Panamá. Diciembre 2014. Recuperado de http://www.mef.gob.pa/es/Documents/PEG\%20 PLAN\%20ESTRATEGICO\%20DE\%20GOBIERNO\%202015-2019.pdf

Hernández, Mario; Martínez, Rolando y Patrie, Justin. Correction: "Reputational Risk Remains Key Issue for Panama Banks". FitchRatings. 17 de marzo de 2017. Recuperado de https://www.fitchratings.com/site/pr/1020745

International Monetary Fund. Panama: Detailed Assessment Report - FATF Recommendations for Anti-Money Laundering and Combating the Financing of Terrorism. Washington, D.C.: International Monetary Fund. 2014. Recuperado de http://www.imf.org/external/ pubs/ft/scr/2014/cr1454.pdf

James, Henry. "Let's tax anonymous wealth!"; en Global Tax Fairness, Pogge, Thomas y Mehta, Krishen. Oxford: Oxford University Press, 2016.

Klaus Schwab, ed. Global Competitiveness Report 2016-2017. Ginebra: Foro Económico Mundial, 2016.

Ministerio de Economía y Finanzas, Dirección de Análisis Económico y Social. Informe Económico y Social 2016. Panamá: Ministerio de Economía y Finanzas. Recuperado de www.mef.gob.pa/es/informes/Documents/Informe $\% 20$ Economico $\% 20 y \% 20$ social $\% 20 \% 20-\% 20$ anual $\% 202016 . p d f$

Naciones Unidas. Informe del Representante Especial del Secretario General para la cuestión de los derechos humanos y las empresas transnacionales y otras empresas, John Ruggie. Naciones Unidas, 2011.

Naciones Unidas. Ilicit financial flows, human rigths and the post-2015 development agenda. Naciones Unidas, 2015.

Naciones Unidas. Estudio final sobre las corrientes financieras ilícitas, los derechos humanos y la Agenda 2030 para el Desarrollo Sostenible del Experto Independiente sobre las consecuencias de la deuda externa y las obligaciones financieras internacionales conexas de los Estados para el pleno goce de todos los derechos humanos, sobre todo los derechos económicos, sociales y culturales. Naciones Unidas, 2016.

Naciones Unidas. Documento básico que forma parte integrante de los informes de los estados partes. Panamá: Naciones Unidas, 2017.

OCDE, Global Forum on Transparency and Exchange of Information for Tax Purposes: Peer Reviews: Panama 2016: Phase 2: Implementation of the Standard in Practice. París: OCDE. 2016.

OCDE, CEPAL, Centro Internacional de Agricultura Tropical, Banco Interamericano de Desarrollo, Estadísticas Tributarias en América Latina y el Caribe 2017. París: OCDE, 2017. Recuperado de www.keepeek.com/Digital-Asset-Management/oecd/taxation/ revenue-statistics-in-latin-america-and-the-caribbean-2017_rev_lat_car-2017-enfr\#page46 
Solís, Alma. "Centro Bancario de Panamá podría cambiar forma de medir depósitos". ANPanamá. 14 de julio de 2013. Recuperado de http://www.anpanama.com/893-Centro-Bancario-de-Panama-podria-cambiar-forma-de-medir-depositos.note.aspx

Stiglitz, Joseph E. y Pieth, Mark, "Why we left the Panama Commission", Time, 10 de agosto de 2016. Recuperado de http://time.com/4446733/joseph-stiglitz-panama-commission/

Superintendencia de Bancos de Panamá. Financial Studies Division. Panamá: Superintendencia de Bancos de Panamá, 2017.

Juan Pablo Bohoslavsky. Argentino. Actual Experto Independiente de Deuda Externa y Derechos Humanos de la ONU. Antes trabajó para la Conferencia de las Naciones Unidas sobre Comercio y Desarrollo (UNCTAD) y fue consultor del Estado argentino y de la Comisión Económica para América Latina y el Caribe (CEPAL). Se recibió de abogado en la Universidad Nacional del Comahue (Patagonia, Argentina), Magister en Derecho Empresario en la Universidad Austral (Buenos Aires, Argentina) y Doctor en Derecho en la Universidad de Salamanca (España). Fue Hauser Global Fellow en la Universidad de Nueva York (Estados Unidos) e investigador posdoctoral en el Instituto Max Planck de Derecho Público Comparado y Derecho Internacional (Heidelberg, Alemania). Ha publicado numerosos artículos y libros sobre deuda, inversiones y derechos humanos. Su último libro, coeditado con Kunibert Raffer, es Sovereign Debt Crises: What Have we learned?, publicado en el año 2007.

Contacto: annuario.iis@ucr.ac.cr

ORCID: 0000-0001-7038-8301 